\title{
Chemical Properties of Pectin from Industry Hot and Cold Break Tomato Products
}

\author{
Hui H. Chong1, Senay Simsek ${ }^{2}$, Bradley L. Reuhs ${ }^{1^{*}}$ \\ ${ }^{1}$ Department of Food Science Whistler Center for Carbohydrate Research, Purdue University, West Lafayette, \\ USA \\ ${ }^{2}$ Department of Plant Sciences, North Dakota State University, Fargo, USA \\ Email: "breuhs@purdue.edu
}

Received 26 April 2014; revised 2 June 2014; accepted 10 June 2014

Copyright (C) 2014 by authors and Scientific Research Publishing Inc.

This work is licensed under the Creative Commons Attribution International License (CC BY).

http://creativecommons.org/licenses/by/4.0/

(c) (i) Open Access

\begin{abstract}
Tomato processing includes a break step, which involves rapid heating of freshly chopped tomatoes to $>9^{\circ} \mathrm{C}$ for hot break, or $60^{\circ} \mathrm{C}$ to $77^{\circ} \mathrm{C}$ for cold break. Pectolytic enzyme deactivation is believed to be the key element in the hot break step; therefore, pectin content of different products should be qualitatively distinct. The objective of this study was to investigate the effect of hot break versus cold break on the cell-wall pectin of tomato. Cell-wall pectin from hot and cold break tomato products was isolated and analyzed for carbohydrate composition, degree of polymerization, and degree of esterification. The results showed no observable differences in the cell-wall pectin isolated from the two products, indicating that there was no significant pectolytic breakdown of the tomato in the cold break product, and the pectin might not, by itself, contribute to the differences in the final product viscosity resulting from the two processing techniques.
\end{abstract}

\section{Keywords}

Tomato Processing, Pectin Methylesterase, Endopolygalacturonase, Pectin, Hot Break, Cold Break

\section{Introduction}

Pectin is a family of complex polysaccharides found in the middle lamella and primary cell walls of plants. The primary class of pectin in tomato is homogalacturonan (HGA), which consists of linear chains of $\alpha$-1,4-linkedd-galacturonic acid with some carboxyl groups in the methyl ester form [1]. HGA is further defined as low methoxyl pectin, with a degree of esterification (DE) $<50 \%$, and high methoxyl pectin, with a DE $>50 \%$ [2]. Pectin contributes significantly to the viscosity of food products, and it is believed that the DE and the degree of

"Corresponding author. 
polymerization (DP) of the tomato pectin are impacted during tomato processing [3] [4].

Industry employs two distinct initial tomato processing methods that result in very different products: The hot break method, which involves a processing temperature of $90^{\circ} \mathrm{C}$ or higher, and the cold break method, in which the processing temperature is $77^{\circ} \mathrm{C}$ or lower. Hot break results in a much more viscous product, and is used for ketchup, sauces, pastes, etc. [5], whereas cold break yields a product with better flavor and color retention, and is used for less viscous products, such as tomato juice. The difference in viscosity has been attributed to the inactivation of enzymes involved in the catabolism of pectin at the higher temperature (Sanchez et al., 2002), primarily pectin methylesterase (PME) and endopolygalacturonase (EPG).

A recent study showed that when tomatoes were subjected to a laboratory simulation of hot and cold break processing, there were no detectable differences in the DE and DP of the pectin isolated from the respective products [6]. The laboratory cold break protocol included a 24 min hold time at room temperature, prior to heating to $94^{\circ} \mathrm{C}$ in a steam jacketed kettle, to allow PME and EPG activity to catabolize the pectin. However, that simulation lacked the pressure and shear that would be found in a large scale industrial processing system. Therefore, this study focused on hot and cold break Roma tomato products from the Red Gold ${ }^{\circledR}$ Company, which had been subjected to the much more severe industrial processing conditions. These products were analyzed for their physical properties and basic composition, and the pectin was then extracted for composition, DP, and DE analyses.

\section{Experimental Procedures}

Tomato products were supplied by Red Gold Inc. (Elwood, IN). Red Gold received the pre-processed tomato preparations from Los Gatos Tomato Products (Huron, CA). The major difference between the two tomato pastes was the break temperature, although the finisher screen sizes were also different. For each experiment, $300 \mathrm{~g}$ of hot and cold break tomato preparations were diluted with double distilled water to the initial obrix of the fresh tomatoes used in the previous tomato processing study [6]. Aliquots of the two preparations were used directly for chemical and viscosity analyses, as well as pectin extraction.

\subsection{Viscosity Analyses}

\subsubsection{Precipitate Weight Ratio}

Approximately $200 \mathrm{~g}$ of each sample was centrifuged at $12,800 \times \mathrm{g}$ for $30 \mathrm{~min}$ at $4^{\circ} \mathrm{C}$. The supernatant was removed for serum viscosity analysis (below). The pre-weighed centrifuge bottles with the centrifugate pellet (precipitate) were inverted for 3 minutes to drain off the remaining supernatant, weighed (triplicate samples for each), and the precipitate weight ratio (PPT) was calculated for each [7].

\subsubsection{Serum Viscosity}

Serum viscosity was analyzed using size 100 Cannon-Fenske capillary viscometer (The Lab Depot, Alpheretta, GA), as previously described [8] [9]. The collected serum was filtered through Whatman No. 1 filter paper. Seven $\mathrm{ml}$ of serum was pipetted into the viscometer, which was immersed in a water bath at $25^{\circ} \mathrm{C}$. The serum was allowed to equilibrate 10 minutes, prior to measurement.

\subsubsection{Brookfield Viscosity}

A Brookfield Viscometer model DV II (Brookfield Engineering Laboratories Inc., Middleboro, MA) with spindle 31 was used to measure the apparent viscosity of the tomato preparations $\left(22.5^{\circ} \mathrm{C}\right)$, according to the manufacturer's instructions.

\subsection{Chemical Analysis}

\subsubsection{Colorimetric Assays}

The Lowry assay was used for the determination of total protein content [10], with bovine serum albumin as the standard. The Anthrone assay was used to determine the neutral sugar content [11], with glucose (Glu) as the standard. The uronic acid content was determined by the m-hydroxydiphenyl-sulfuric acid method [12], with galacturonic acid (GalA) as the standard. The amylose content was determined using the iodine-binding assay [13], using starch as the standard. 


\subsubsection{Pectin Extraction and Analysis}

The pectin-containing cell walls were extracted from the tomato preparations using an aqueous potassium phosphate method, followed by solubilization of pectic polysaccharides from the cold potassium phosphate-insoluble cell walls [14]. The pectin preparation was then treated with $\alpha$-amylase to remove any starch. The glycosyl residue content was determined by gas chromatographic (GC) analysis of the trimethylsilyl (TMS)-methyl glycoside derivatives [15] [16].

A comparative size-range estimation of the pectic polysaccharides was made by medium pressure size exclusion chromatography (SEC), using a Tricond column $(300 \mathrm{~mm} \times 10 \mathrm{~mm})$ packed with SephacrylTM S-400 (Amersham Bioscience, Piscateway, NJ). Samples were eluted with an ammonium formate (50 $\mathrm{mM} ; \mathrm{pH} 5.5)$ eluent, at a flow rate of $0.45 \mathrm{ml} / \mathrm{min}$, and fractions were collected (3 min/fraction). Aliquots of each fraction were assayed for uronic acid, as above [12], in order to generate a pectin elution profile. The size ranges were estimated by comparison to dextran standards.

The DE of the extracted pectin was estimated by proton nuclear magnetic resonance (1H NMR) spectroscopy [17]. The samples $(\sim 300 \mu \mathrm{g})$ were dissolved in $0.7 \mathrm{ml}$ deuterium oxide (D2O) and $1 \mathrm{H}$ NMR spectra were obtained at $25^{\circ} \mathrm{C}$ using a Varian UNITY INOVA 300 NMR spectrometer (Varian Inc, Palo Alto, CA).

\subsection{Statistical Analysis}

A p-value of less than 0.05 was considered significant for all analyses of variance and t-tests in the study using SAS software (SAS Institute Inc., Cary, NC).

\section{Results}

\subsection{Viscosity}

Viscosity measurements obtained from commonly used methods, which included Brookfield, precipitate weight ratio, and serum viscosity are given in Table 1 . Although the hot break preparation was shown to be more viscous by all three analyses, the serum viscosity measurement yielded the most significant difference. These analyses showed that these particular hot and cold break samples were typical for industrial preparations.

\subsection{Chemical Assays}

The general chemical properties (total neutral sugar, acidic sugar, starch, and protein content) of both tomato preparations where determined by colorimetric assays. As expected, the results showed no significant differences between the samples (Data not shown) because unless the glycosyl residues are destroyed during processing, rather than just depolymerization of the polysaccharides, the composition should not differ when the tomato source is the same.

\subsection{Pectin Analysis}

The pectic polysaccharides were extracted from the hot break and cold break tomato preparations by a method that has been shown to effectively solubilize pectin from fresh plant tissue [6] [14]. These samples were then analyzed by GC to establish the glycosyl residue composition. The composition results showed that both extracted pectin preparations contained substantial amounts of galacturonic acid (GalA), however, GalA constituted only about $30 \%$ of the detected carbohydrate. The remaining $70 \%$ of the detected carbohydrate was split between glucose (Glc) and the other neutral residues, including arabinose (Ara), rhamnose (Rha), xylose (Xyl), mannose (Man), and galactose (Gal). Glc, which was the major glycosyl residue component in the extracts, was

Table 1. Different methods for viscosity measurement of hot and cold break tomato preparations.

\begin{tabular}{cccc}
\hline Process & Brookfield viscosity & PPT $^{\mathrm{a}}(\%)^{\mathrm{b}}$ & Serum viscosity (sec) \\
\hline Kb n & & 22.57 & 226 \\
Cold Break & 7358.160 .30 & 15.44 & 107 \\
\hline
\end{tabular}

${ }^{\mathrm{a}} \mathrm{PPT}=$ Precipitate Weight Ratio; ${ }^{\mathrm{b}}$ Significant at $\mathrm{P}<0.05$. 
not detected in the pectin extracts from the laboratory hot and cold break products in the past study [6].

\subsection{Degree of Polymerization}

The DP of the pectin from the hot and cold break tomato preparations was examined by SEC, using a SephacrylTM S-400 SEC column. Aliquots from the collected fractions were assayed for uronic acid content and the results were plotted as a pectin elution profile. As in the previous study [6], the extracted pectin from both tomato preparations eluted in the separation range of the column, without the presence of void peak (Figure 1). The peaks from both pectin samples had virtually identical start and stop points, showing that the pectin in each had the same size range. There were minor differences in the peak maximum, but that varied from run to run. A comparison to standards indicated that, as in the previous study [6], the size range was approximately $1.5 \times 10^{5}$ $-1.5 \times 10^{6}$. This is in good agreement with previous estimates for the size range of non-degraded pectin [3] [18] [19].

\subsection{Degree of Esterification}

The pectin was collected from the SEC separation step, and the DE was analyzed by NMR analysis. The H-4 protons, which resonate at approximately $4.4 \mathrm{ppm}$, are shifted downfield (to a higher chemical shift) for those galacturonosyl residues that are methylesterified on the carboxyl group [17]. The results showed no significant differences in the DE of the two samples. Both of the spectra had the same ratio of the integration values for the relevant resonances, $4.44 \mathrm{ppm}$ and $4.4 \mathrm{ppm}$, and it was estimated that both extracted pectins had a DE of approximately of $65 \%$ - $75 \%$ (Figure 2).

\section{Discussion}

As in the past report [6], there was no observed difference in the DP or DE of the pectin from hot break and cold break processing. This was clearly shown by the SEC and NMR analyses. Furthermore, the fact that DE was similar in both samples supports the SEC data, as PME activity would be necessary for significant EPG activity to take place. Despite the similarity in pectin quality, the hot break material was, in fact, much more viscous than the cold break, and the analyses showed that the serum viscosity was significantly different between the two samples. In contrast, the laboratory hot break material was not more viscous than the cold break, so it appears that the industrial processing has effects on the product beyond the simple heat effects.

In the past report [6], in which the tomatoes were processed without the pressure and shear of the industrial system, composition analysis of the solubilized pectin preparation showed a high degree of purity, with GalA constituting approximately 77\% of the detected carbohydrate in the GC analyses of both hot break and cold break preparations. This level of purity for the pectin solubilization was also found using the same protocol for plant leaf material [14]. However, when the exact same protocol was applied to industrial tomato products, the GalA was only about $30 \%$ of the solubilized carbohydrate. Glc accounted for approximately $35 \%$ and the other

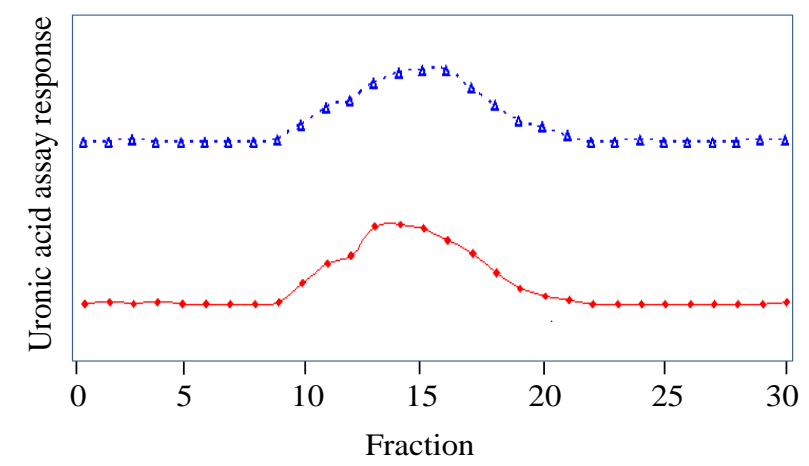

Figure 1. The Sephacryl ${ }^{\mathrm{TM}}$ S-400 SEC pectin elution profiles of pectin extracted from industry (top) hot break tomato product and (bottom) cold break tomato product. The collected fractions were assayed for uronic acid content by colorimetric analysis [12]. 


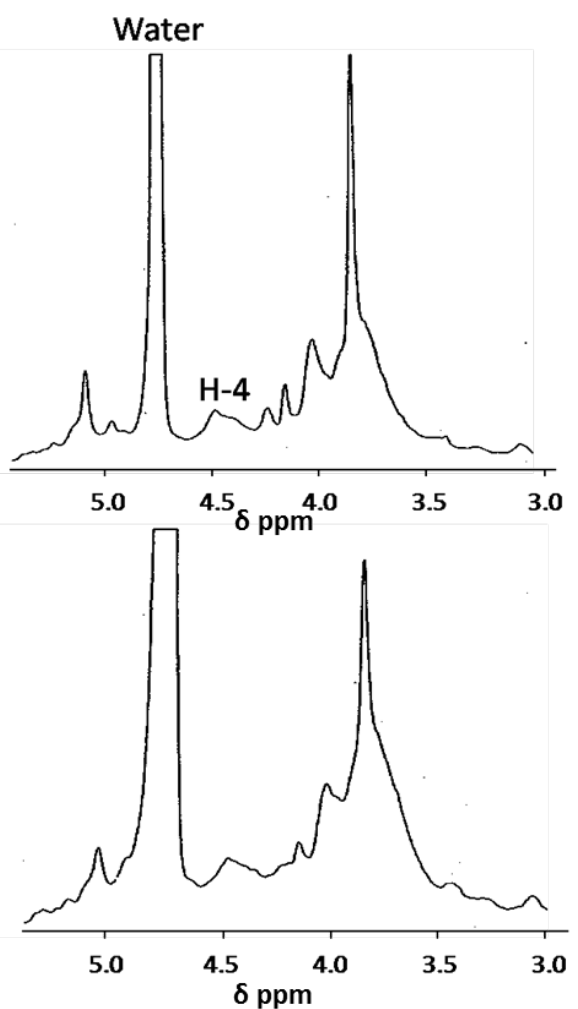

Figure 2. ${ }^{1} \mathrm{H}$ NMR spectra of (top) pectin extracted from hot break product, and (bottom) pectin extracted from cold break product. Although there is not baseline resolution, the integration values from a forced baseline integration indicated that both have approximately a $65 \%-75 \%$ degree of esterification (DE), as described in [17].

neutral glycosyl residues, including Xyl and Man, accounted for the remaining 35\%. These components were not found in even trace quantities in the previous study; only Ara, Rha, and Gal were detected, and those sugars are commonly found in pectic preparations. Therefore it appears that one effect of the industrial processing is to make various cell wall components more soluble.

Since this was noted in both preparations, hot and cold break, it must be the other factors in industrial processing that are responsible for this outcome, and microscopy evidence supports this. When the hot and cold break material from the laboratory preparations were examined by light microscopy, the tomato cell structure was found to be largely intact, with many whole, undisrupted cells. In contrast, the cell structure in the industry samples was almost completely disrupted.

\section{Conclusion}

Overall, different processing techniques did not affect chemical composition when applied to tomato pastes from the same tomato source. However, significant $(\mathrm{P}<0.05)$ differences were observed for viscosity and PPT between hot and cold break processing techniques. Even though, both samples had similar pectin quality, much higher viscosity was observed for the hot break material was. Since, these differences were not seen in tomato pastes processed in the laboratory, there must be some factors in the industrial process creating these differences. This hypothesis was supported by the microscopy of the samples, which showed the near complete disruption of cells in the tomato pastes.

\section{References}

[1] Voragen, A.G.J., Pilnik, W., Thibault, J.F., Axelos, M.A.V. and Renard, C.M.G.C. (1995) Pectins. Food Polysaccha- 
rides and Their Applications. Marcel Pekker Inc., San Diego.

[2] Whistler, R. and BeMiller, J.N. (1997) Pectins. Carbohydrate Chemistry for Food Scientists. Eagan Press, St. Paul.

[3] Sharma, S.K., Liptay, A. and Le Maguer, M. (1998) Molecular Characterization, Physico-Chemical and Functional Properties of Tomato Fruit Pectin. Food Research International, 30, 543-547. http://dx.doi.org/10.1016/S0963-9969(98)00017-9

[4] Anthon, G.E., Sekine, Y., Watanabe, N. and Barrett, D.M. (2002) Thermal Inactivation of Pectin Methylesterase, Polygalacturonase, and Peroxidase in Tomato Juice. Journal of Agricultural and Food Chemistry, 50, 6153-6159.

[5] Goodman, C.L., Fawcett, S. and Barringer, S.A. (2002) Flavor, Viscosity, and Color Analyses of Hot and Cold Break Tomato Juices. Journal of Food Science, 67, 404-408.

[6] Chong, H.H., Simsek, S. and Reuhs, B.L. (2009) Analysis of Cell-Wall Pectin from Hot and Cold Break Preparations. Food Research International, 42, 770-772. http://dx.doi.org/10.1016/j.foodres.2009.02.025

[7] Takada, N. and Nelson, P.E. (1983) A New Consistency Method for Tomato Products: The Precipitate Weight Ratio. Journal of Food Science, 48, 1460-1462. http://dx.doi.org/10.1111/j.1365-2621.1983.tb03516.x

[8] Caradec, P.L., Nelson, P.E. and Takada, N. (1985) Tomato Products: A New Serum Separation Measurement. Journal of Food Science, 50, 1493-1494. http://dx.doi.org/10.1111/j.1365-2621.1985.tb10509.x

[9] Caradec, P.L. and Nelson, P.E. (1985) Effect of Temperature on the Serum Viscosity of Tomato Juice. Journal of Food Science, 50, 1497-1498. http://dx.doi.org/10.1111/j.1365-2621.1985.tb10511.x

[10] Lowry, O.H., Rosebrough, N.J., Farr, A.L. and Randall, R.J. (1951) Protein Measurement with the Folin Phenol Reagent. The Journal of Biological Chemistry, 193, 265-275.

[11] Dische, Z. (1962) Color Reactions of Pentoses. In: Whistler, R.L. and Wolfrom, M.L., Eds., Methods in Carbohydrate Chemistry, Academic Press, New York, 475-514.

[12] Blumenkrantz, N. and Asboe-Hansen, G. (1973) New Method for Quantitative Determination of Uronic Acids. Analytical Biochemistry, 54, 484-459. http://dx.doi.org/10.1016/0003-2697(73)90377-1

[13] Chinnaswamy, R. and Bhattacharya, K.R. (1986) Characteristics of Gel-Chromatographic Fractions of Starch in Relation to Rice and Expanded Rice-Product Qualities. Starch-Stärke, 38, 51-57. http://dx.doi.org/10.1002/star.19860380205

[14] Reuhs, B.L., Glenn, J., Stephens, S.B., Kim, J.S., Christie, D.B., Glushka, J.G., Zablackis, E., Albersheim, P., Darvill, A.G. and O’Neill, M.A. (2004) L-Galactose Replaces L-Fucose in the Pectic Polysaccharide Rhamnogalacturonan II Synthesized by the L-Fucose-Deficient mur1Arabidopsis Mutant. Planta, 219, 147-157. http://dx.doi.org/10.1007/s00425-004-1205-X

[15] York, W.S., Darvill, A.G., McNeil, M. and Albersheim, P. (1985) 3-Deoxy-D-manno-2-octulosonic Acid (Kdo) Is a Component of Rhamnogalacturonan II, a Pectic Polysacchride in the Primary Cell Walls of Plants. Carbohydrate Research, 138, 109-126. http://dx.doi.org/10.1016/0008-6215(85)85228-9

[16] McNeil, M., Darvill, A.G. and Albersheim, P. (1982) Structure of Plant Cell Walls. XII. Identification of Seven Diffe-

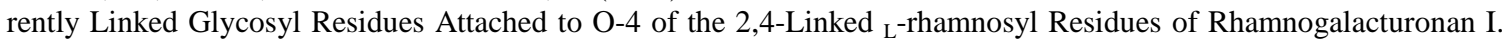
Plant Physiology, 70, 1586-1591. http://dx.doi.org/10.1104/pp.70.6.1586

[17] Rosenbohm, C., Lundt, I., Christensen, T.M.I.E. and Young, N.W.G. (2003) Chemically Methylated and Reduced Pectins: Preparation, Characterisation by 1H NMR Spectroscopy, Enzymatic Degradation and Gelling Properties. Carbohydrate Research, 338, 637-649. http://dx.doi.org/10.1016/S0008-6215(02)00440-8

[18] Chou T.D. and Kokini, J.L. (1987) Reological Properties and Conformation of Tomato Paste Pectins, Citrus and Apple Pectins. Journal of Food Science, 52, 1658-1664. http://dx.doi.org/10.1111/j.1365-2621.1987.tb05900.x

[19] Hurtado, M., Greve, L.C. and Labavitch, J.M. (2002) Changes in Cell Wall Pectins Accompanying Tomato (Lycopersicon esculentum Mill.) Paste manufacture. Journal of Agricultural and Food Chemistry, 50, 273-278. 
Scientific Research Publishing (SCIRP) is one of the largest Open Access journal publishers. It is currently publishing more than 200 open access, online, peer-reviewed journals covering a wide range of academic disciplines. SCIRP serves the worldwide academic communities and contributes to the progress and application of science with its publication.

Other selected journals from SCIRP are listed as below. Submit your manuscript to us via either submit@scirp.org or Online Submission Portal.
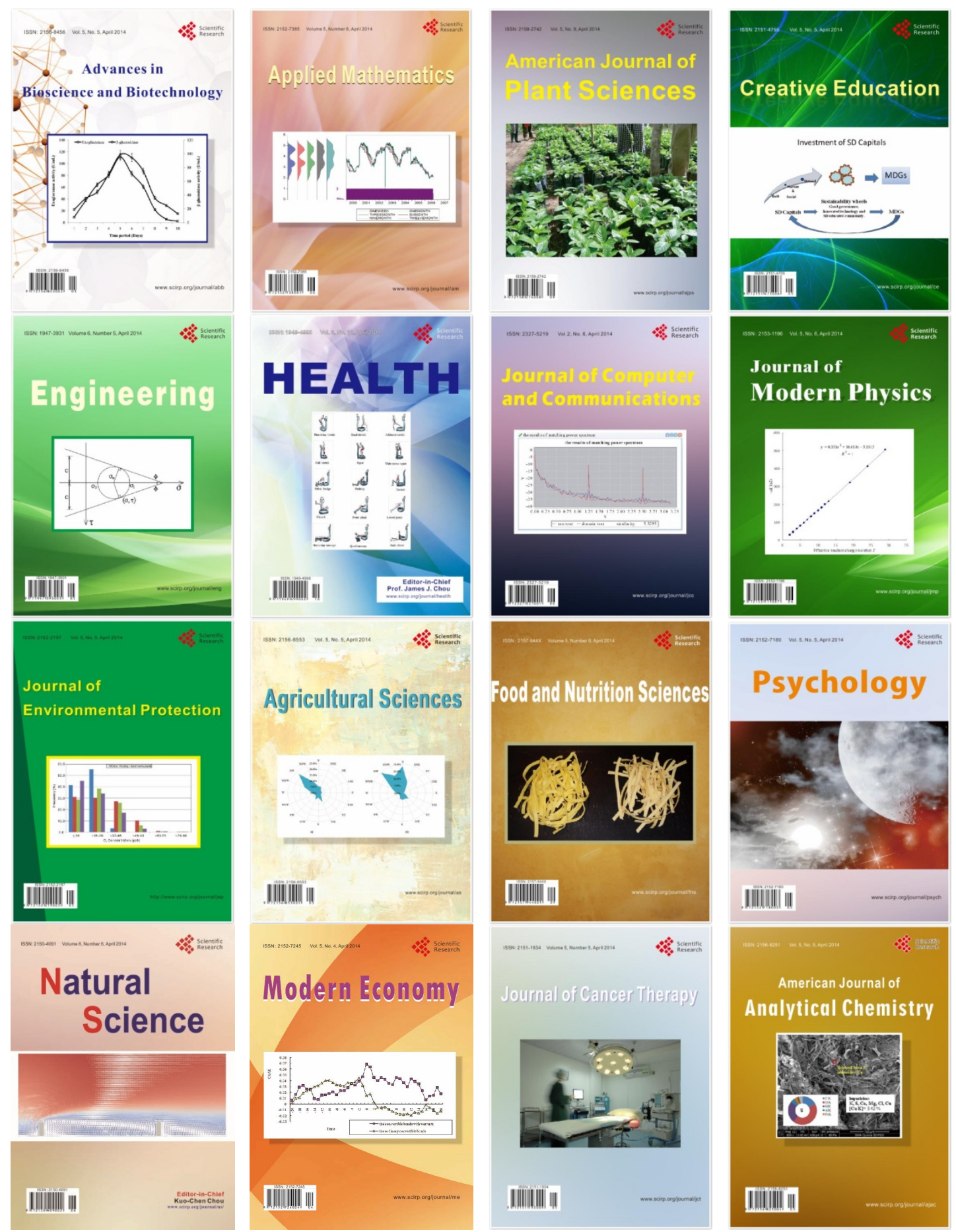